\title{
Fighting parasites and predators: How to deal with multiple threats?
}

\author{
Olivia Hesse ${ }^{1 \dagger}$, Wolfgang Engelbrecht ${ }^{1 \dagger}$, Christian Laforsch ${ }^{1,2^{*}}$ and Justyna Wolinska ${ }^{1}$
}

\begin{abstract}
Background: Although inducible defences have been studied extensively, only little is known about how the presence of parasites might interfere with these anti-predator adaptations. Both parasites and predators are important factors shaping community structure and species composition of ecosystems. Here, we simultaneously exposed Daphnia magna to predator cues (released by the tadpole shrimp, Triops, or by a fish) and spores of the yeast parasite Metschnikowia sp. to determine how life history and morphological inducible defences against these two contrasting types of predators are affected by infection.

Results: The parasite suppressed some Triops-induced defences: Daphnia lost the ability to produce a greater number of larger offspring, a life-history adaptation to Triops predation. In contrast, the parasite did not suppress inducible defences against fish: induction (resulting in smaller body length of the mothers as well as of their offspring) and infection acted additively on the measured traits. Thus, fish-induced defences may be less costly than inducible defences against small invertebrate predators like Triops; the latter defences could no longer be expressed when the host had already invested in fighting off the parasite.

Conclusions: In summary, our study suggests that as specific inducible defences differ in their costs, some might be suppressed if a target prey is additionally infected. Therefore, adding parasite pressure to predator-prey systems can help to elucidate the costs of inducible defences.
\end{abstract}

Keywords: Daphnia, Host-parasite, Inducible defences, Metschnikowia sp., Multiple stressors, Phenotypic plasticity, Predator-prey

\section{Background}

Inducible defences, which are found among various groups of organisms, can evolve when there is spatial or temporal heterogeneity in predation risk [e.g. [1,2]]. Often, such defences are triggered by predator-released chemical cues, so called kairomones [3] and may be additionally altered in response to hetero- and conspecific alarm cues $[4,5]$. Although beneficial when predation is high, inducible defences are assumed to come at a cost which could potentially be saved in predator free environments. If no costs exist, defences should be expressed permanently [e.g. [6,7]]. The costs to sustain such an adaptive defence system have been classified as different

\footnotetext{
*Correspondence: laforsch@zi.biologie.uni-muenchen.de

'Equal contributors

'Department of Biology II, Ludwig-Maximilians-University Munich,

Grosshaderner Str 2, 82152 Planegg-Martinsried, Germany

${ }^{2}$ GeoBio Center, Ludwig-Maximilians-University Munich, Munich, Germany
}

types: First, there might be costs related to the maintenance of sensory or regulatory systems needed to detect environmental conditions. Secondly, energy and resource investment might be needed for constructing, maintaining and operating the defensive traits. Further costs can arise from self damage (e.g. autotoxicity), opportunity costs like the long-term consequences of allocation or developmental constraints and finally, environmental costs (expressing a suboptimal phenotype in a given environment) $[1,8]$. Still, the existence, modality and extent of these costs are debated and many empirical studies have found only negligible to weak costs [e.g. $[9,10]]$; reviewed in 8 . However, while costs may not be apparent under optimal conditions, there may be a reduction in fitness under conditions of stress [11].

Parasites are a common threat across ecosystems [12]. Thus, many organisms are simultaneously prey for predators and hosts for parasites [13]. Often the response 
to one stressor has further implications regarding an individual's defence towards another stressor. For example, parasite-mediated alterations of anti-predator behavior have been shown in amphibians infected by fungi [14] and crickets parasitized with nematodes [15]. Freshwater snails respond to the presence of predatory crayfish with predator avoidance behavior but, at the same time, suffer a reduced ability to defend against potential pathogens [16]. Similarly, the long-term exposure of hamsters to an overdose of weasel odor can suppress the immune system [17] and likewise the immune defense of damselflies is suppressed under presence of fish predators [18]. Interestingly, another study in damselflies showed an increased investment into some components of the immune system in the presence of predatory dragonflies [19] suggesting that induction of the immune defence is differently affected depending on the type of predator the host is exposed to.

A suitable model organism to investigate the effects of parasites on inducible defences is the "water flea" Daphnia, a small planktonic crustacean. Daphnia is known to change its morphology, life history and behavior in response to predators (reviewed in [20]) and is also commonly studied in host - parasite interactions [e.g. $[21,22]]$. Although Daphnia are often exposed to predators and parasites simultaneously, there are few studies that have investigated the effects of infection on inducible defences. It has been shown that Daphnia galeata can still express inducible defences against fish, regardless of infection with protozoan or yeast parasites $[23,24]$. The same was true for D. magna infected with a bacterial parasite [25]. In contrast, simultaneous exposure of $D$. magna to the same bacterial parasite but to an invertebrate predator (phantom midge larvae), resulted in antagonistic or additive effects on some host life history traits [26]. The different outcome of the two latter studies may have resulted from the different predator types involved.

In general, large predators prefer to hunt larger prey and thus exert a selective pressure for the prey to mature earlier at a smaller size, whereas small predators are limited to small prey and select for delayed prey maturity at larger size [e.g. [27,28]]. The dominant large predators on Daphnia are planktivorous fish. In response to fish kairomone, D. magna mature earlier at a smaller body size, develop elongated tail spines and produce more but smaller offspring e.g. [29,30]. Among the invertebrate predators of $D$. magna are the tadpole shrimps, Triops [31,32], which are limited to smaller prey by the size of their food groove and the opening width of the mandibles. D. magna respond to Triops by getting 'bulky' (i.e. they increase in body length and width) and by developing elongated tail spines [31,33]. Since the Triops-induced defence contrasts the induced response of Daphnia towards fish, the influence of parasites on these two types of inducible defences might not be the same. Given the variability in Daphnia's response to parasites and predators, it is difficult to elucidate general costs imposed by simultaneous exposure to both threats.

Our study aims to analyze the influence of parasites on the expression of the two contrasting anti-predator defence strategies and to compare potential costs of these defences. To investigate this question we infected D. magna with the parasite Metschnikowia sp. (family Hemiascomycetes, [34]), which causes major reductions in host life span and fecundity [35-37], and exposed them to two contrasting types of predators, fish and Triops.

\section{Methods}

\section{Origin and care of host, parasite and predators}

We tested a single Daphnia magna clone isolated from a temporary pond in Oxford, England. Daphnia were kept in climate chambers at $20 \pm 0.5^{\circ} \mathrm{C}$ with a constant photoperiod (15 h light and $9 \mathrm{~h}$ dark) in artificial medium (ultrapure water, phosphate buffer and trace elements) and were fed three times per week with green unicellular algae (Scenedesmus obliquus). For three generations prior to the experiment, Daphnia were kept individually in $100 \mathrm{ml}$ of medium which was exchanged every third day and fed daily with $2 \mathrm{mg} \mathrm{Cl}^{-1}$ of $S$. obliquus. The Metschnikowia sp. strain was isolated from lake Ammersee in Germany, and cultured on the same D. magna clone as used in the experiment. Two predators were tested: the tadpole shrimp, Triops cancriformis, and the fish, Rhodeus amarus (hereafter referred to as 'Triops' and 'fish', respectively). A clonal line of Triops was provided by Dr. E. Eder (Zoological Institute, University of Vienna). Different size classes were raised separately in 81 aquaria filled with semiarticifial medium (wellwater and aqua bidest. 1:1) and fed with Chironomidae and commercial fish food (Grana Discus, JBL GmbH \& Co. KG, Germany) ad libitum. The fish were obtained from a commercial store; 20 individuals were kept in a $100 \mathrm{l}$ aquarium and fed with commercial fish food. The experimental research on animals followed internationally recognized guidelines.

\section{Preparation of kairomone media}

Three types of media were prepared daily: 1) Triops kairomone (a 21 beaker was stocked with two Triops for $24 \mathrm{~h}$; Triops size: $2-3 \mathrm{~cm}$ ), 2) fish kairomone (a $5 \mathrm{l}$ beaker was stocked with one fish for $24 \mathrm{~h}$; fish size: 6-7 cm), and 3) control medium (no kairomone). The fish density was similar to that used in previous studies [e.g. [23,24]]. The applied Triops density is lower to that found in natural concentrations of this predator (up to 2500 Triops $/ \mathrm{m}^{2}$ in natural ponds, [38]) 
and adequate for defence induction in D. magna [31]. The predators were fed with a commercial fish food (preliminary experiments showed no effect of the fish food on the defence expression in Daphnia, CL, unpublished data); the same amount of fish food was added daily to the kairomone-free treatments. Additionally, predators were fed adult D. magna of the same clone as the experimental units: each Triops obtained approximately 15-20 Daphnia and each fish 30-40 Daphnia per day. Hence, the term 'kairomone' refers not only to cues released by the predators but also to alarm substances released from prey during their consumption by the predator [4]. Prior to use all media were filtered $(0.22 \mu \mathrm{m})$.

\section{Experimental set-up}

D. magna were individually exposed to predator kairomones and/or parasite spores. This resulted in six treatments, with 20 replicates each: one treatment without kairomones and without infection ('control-no parasite'), one without kairomones but with infection ('control - parasite'), two kairomone treatments without infection ('Triops - no parasite' and 'fish - no parasite') and two double-stressed treatments ('Triops - parasite' and 'fish-parasite'). On day 1 , third clutch newborns $(<24 \mathrm{~h})$ from age-synchronized mothers were placed individually in $5 \mathrm{ml}$ of Triops-, fish- or control-medium on a random basis. On days 1 and 3 a parasite spore solution (obtained by homogenization of the infected $D$. magna) was added at a concentration of 2200 (day 1) and 2800 (day 3) spores $\mathrm{ml}^{-1}$. A placebo solution was analogously prepared from the same number of uninfected Daphnia and given to the non-infected treatments. On day 2, $5 \mathrm{ml}$ of medium was added and on day 3 the Daphnia were transferred into $10 \mathrm{ml}$ of new medium. On day 4, an additional $10 \mathrm{ml}$ of medium was added to all jars. From day 5 onwards, all individuals were kept in $40 \mathrm{ml}$ of medium, which was exchanged daily (before, the medium was kept at a small volume to increase the probability of spore ingestion by Daphnia). The Daphnia were fed daily with $2 \mathrm{mg} \mathrm{Cl}^{-1} S$. obliquus (except days 2 and 4, when only $1 \mathrm{mg} \mathrm{Cl}^{-1}$ was added). The experiment lasted 24 days, at which point all infected animals had died.

\section{Recorded parameters}

We collected the following life history and morphological data: 1 ) age at maturity (i.e. the day of $1^{\text {st }}$ clutch release), 2) life span, 3) number of offspring in the first three clutches, 4) body length (distance between the upper edge of the compound eye and the base of the tail spine) after the release of each of three clutches, and 5) body length of five randomly selected offspring per mother from each of the first three clutches (average per clutch was used for statistical analyses). For the morphological measurements we used a digital image-analysis system (Cell^P, Olympus, Hamburg, Germany). Finally, when the Daphnia died the body length was measured and the concentration of mature parasite spores [39] was counted using a Neubauer Improved counting chamber.

\section{Statistical analyses}

All analyses were performed with PASW Statistics (version 18.0). We used a two-way ANOVA with three levels of kairomone treatment (fish, Triops and control) and two levels of infection (parasite and no-parasite). Age at maturity and life span were transformed prior to analysis (Rankit transformation, [40]). A Tukey's PostHoc Test was run to distinguish between the effects of the different kairomone treatments. Parasite spore load was analysed by ANCOVA (with Daphnia body length at death as a covariate) and the interaction of kairomone $\times$ body length was included in the model. Individuals from the parasite treatments which did not become infected $(n=4)$ were excluded from all analyses. Similarly, individuals which died before day 10 (i.e. day when infection was first detectable) were also excluded $(\mathrm{n}=5)$.

\section{Results}

\section{Age at maturity and life span}

Infected Daphnia matured significantly later than noninfected Daphnia whereas Triops and fish exposure led to earlier maturation regardless of infection status (Figure 1, Table 1). In addition, infection led to significant reductions in life span (Figure 1, Table 1).

\section{Number of offspring}

Infected Daphnia produced significantly less offspring than uninfected Daphnia (in the $3^{\text {rd }}$ clutch: $\sim$ three times less; Figure 2a, Table 1). Moreover, none of the infected individuals produced more than three clutches, whereas the uninfected Daphnia produced five clutches by the end of the experiment. Regarding the kairomones, exposure to fish had no effect on the number of offspring, but Triops-exposed Daphnia produced more offspring than controls in the $2^{\text {nd }}$ and $3^{\text {rd }}$ clutch (Figure 2a). However, this effect was suppressed by infection (see infection $\times$ kairomone interaction in the $2^{\text {nd }}$ clutch, Table 1).

\section{Body length}

Infection as well as fish kairomone exposure led to a significant decrease in body length across all three clutches (Figure 2b, Table 1). Daphnia exposed to Triops kairomones were smaller in size, but only when additionally infected (see significant interaction in the $1^{\text {st }}$ clutch, Table 1). The offspring of infected mothers were 

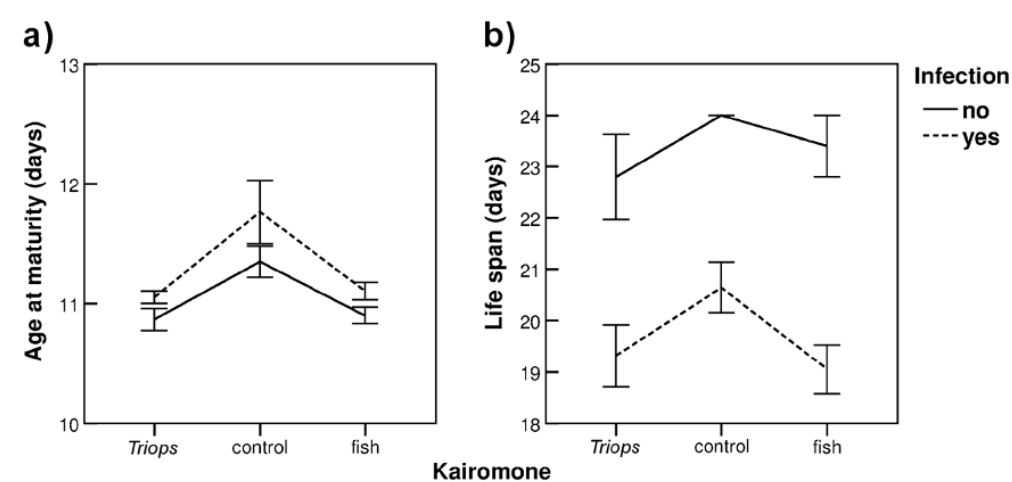

Figure 1 Means ( \pm SE) of (a) age at maturity and (b) life span across three types of medium (Triops kairomone, control, fish kairomone), and for both infected (filled symbols) and non-infected (open symbols) Daphnia magna.

significantly larger in the $1^{\text {st }}$ clutch, but smaller in the $3^{\text {rd }}$ clutch (Figure 2c, Table 1). Although Triops-exposed mothers had larger offspring in their $1^{\text {st }}$ and $3^{\text {rd }}$ clutches, infection suppressed this effect in the $3^{\text {rd }}$ clutch (see significant interaction, Table 1). In contrast, fish-exposed Daphnia produced significantly smaller offspring in all clutches, independent of infection (Figure 2c, Table 1).

\section{Spore load}

Larger Daphnia contained significantly more parasite spores $\left(\mathrm{F}_{1,53}=14.2 ; \mathrm{p}<0.001\right)$. However, kairomones had no effect on the amount of spores $\left(\mathrm{F}_{2,53}=0.3 ; \mathrm{p}=0.708\right)$ and there was no significant kairomone $\times$ body length interaction $\left(F_{2,53}=0.2 ; p=0.783\right.$; Figure 3$)$.

\section{Discussion}

Both tested predator cues had significant effects on the life history and morphology of Daphnia magna. When exposed to fish kairomones, Daphnia matured earlier, at a smaller body size and produced smaller offspring (as in $[29,30])$. Triops-induced D. magna also matured earlier (as in [31]) but at a similar size than the control Daphnia. In addition, their offspring were larger than control offspring. Previous studies on Triops-exposed $D$. magna reported an increase in body width and body length for induced individuals (i.e. "bulkiness") [31]. The lack of such an effect in adult Daphnia in the present study might be caused by clonal differences in response to kairomones, such as have been reported from this [33] and other predator-prey systems [e.g. [41,42]]. In addition, the Daphnia were exposed to the kairomone only after they were released from their mothers' brood pouch. This may account for the less pronounced inducible defences. Previous studies using other Daphnia species have shown that the sensitive phase for induction starts already during embryonic stages, resulting in the offspring from predator-exposed individuals being better defended (i.e. "maternally induced defence") than

Table 1 The effects of infection and kairomone treatments on Daphnia magna life history and morphological traits (two-way ANOVAs)

\begin{tabular}{|c|c|c|c|c|c|c|c|}
\hline \multirow{2}{*}{$\begin{array}{l}\text { Dependent } \\
\text { variable }\end{array}$} & \multirow[t]{2}{*}{ Clutch } & \multicolumn{2}{|c|}{ Infection $(\mathrm{df}=1)$} & \multicolumn{2}{|c|}{ Kairomone $(\mathrm{df}=2)$} & \multicolumn{2}{|c|}{ Infection $\times$ Kairomone $(\mathrm{df}=\mathbf{2}$} \\
\hline & & $F$ & $p$ & $F$ & $p$ & $F$ & $p$ \\
\hline Age at maturity & & 7.7 & 0.006 & 14.3 & $<0.001(\mathrm{~F}, \mathrm{~T})$ & 0.01 & 0.993 \\
\hline Life span & & 124.1 & $<0.001$ & 3 & 0.053 & 0.4 & 0.657 \\
\hline Number of & 1 & 17.6 & $<0.001$ & 0.9 & 0.425 & 0.3 & 0.766 \\
\hline \multirow[t]{2}{*}{ offspring } & 2 & 38.3 & $<0.001$ & 1.9 & 0.156 & 3.5 & 0.034 \\
\hline & 3 & 101 & $<0.001$ & 3.7 & 0.029 & 0.04 & 0.961 \\
\hline \multirow[t]{3}{*}{ Body length } & 1 & 63.6 & $<0.001$ & 19 & $<0.001(\mathrm{~F}, \mathrm{~T})$ & 4.2 & 0.017 \\
\hline & 2 & 124.8 & $<0.001$ & 18.7 & $<0.001(\mathrm{~F}, \mathrm{~T})$ & 1.4 & 0.261 \\
\hline & 3 & 130 & $<0.001$ & 17.7 & $<0.001(\mathrm{~F}, \mathrm{~T})$ & 0.3 & 0.706 \\
\hline Offspring & 1 & 14.7 & $<0.001$ & 12.3 & $<0.001(\mathrm{~F}, \mathrm{~T})$ & 0.9 & 0.411 \\
\hline \multirow[t]{2}{*}{ body length } & 2 & 1,7 & 0.197 & 11.8 & $<0.001(\mathrm{~F})$ & 1.2 & 0.307 \\
\hline & 3 & 70.9 & $<0.001$ & 18.8 & $<0.001(\mathrm{~F})$ & 3.7 & 0.030 \\
\hline
\end{tabular}

Significant values are given in bold. The exact occurrence of significant differences between the kairomone treatments and the control are given as " $\mathrm{F}$ " or "T" for the fish and Triops treatment, respectively. 

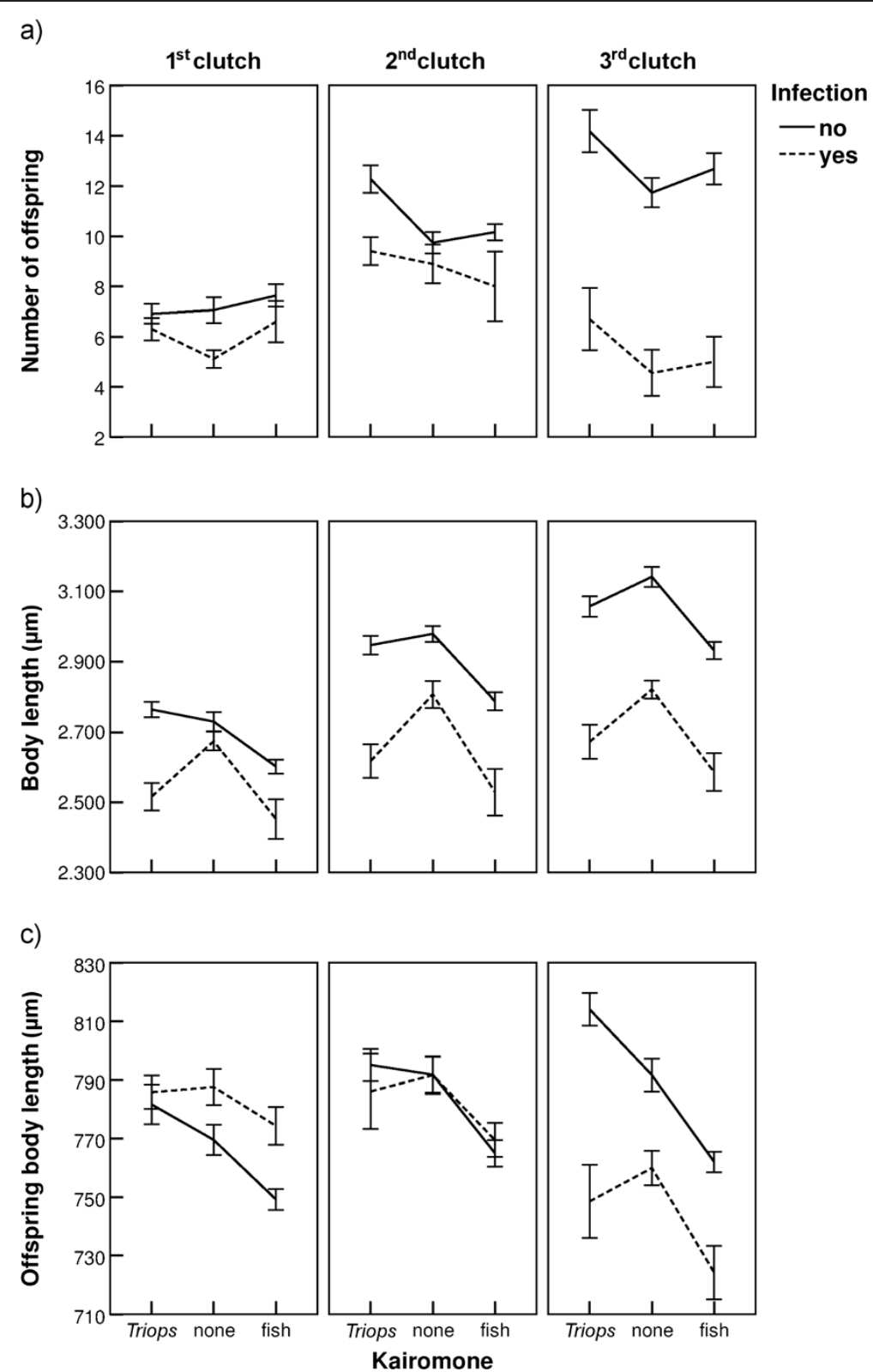

Figure 2 Means ( \pm SE) of (a) number of offspring, (b) body length and (c) offspring body length for $1^{\text {st }}, 2^{\text {nd }}$ and $3^{\text {rd }}$ clutch, across three types of medium (Triops kairomone, control, fish kairomone), and for both infected (filled symbols) and non-infected (open symbols) Daphnia magna. The scale of the $y$-axis is the same across the three presented clutches.

offspring from unthreatened parents $[43,44]$. This seems to be concordant with the observation that the Triopsinduced adult Daphnia did not show an increase in body length while their offspring were significantly larger compared to control individuals.

Regarding the effect of infection, similar to findings from other studies, Metschnikowia-infected Daphnia showed delayed maturity, produced fewer offspring, were smaller in size and died earlier [e.g. [35-37]]. It seems that the parasite consumes resources that could otherwise be invested into host reproduction and growth
[36]. Surprisingly, the first-brood offspring of infected mothers were significantly larger than offspring of noninfected individuals. As the parasite shortens the host's life span and its ability to reproduce, a larger investment into first-brood offspring may be a strategy to maximize the fitness of infected hosts; at least in the presence of invertebrate predators or at low predation risk. This corresponds to the observation that larger offspring are produced in response to unfavourable environmental conditions in Daphnia [e.g. $[45,46]]$, as well as in other organisms [e.g. [47-49]]. 


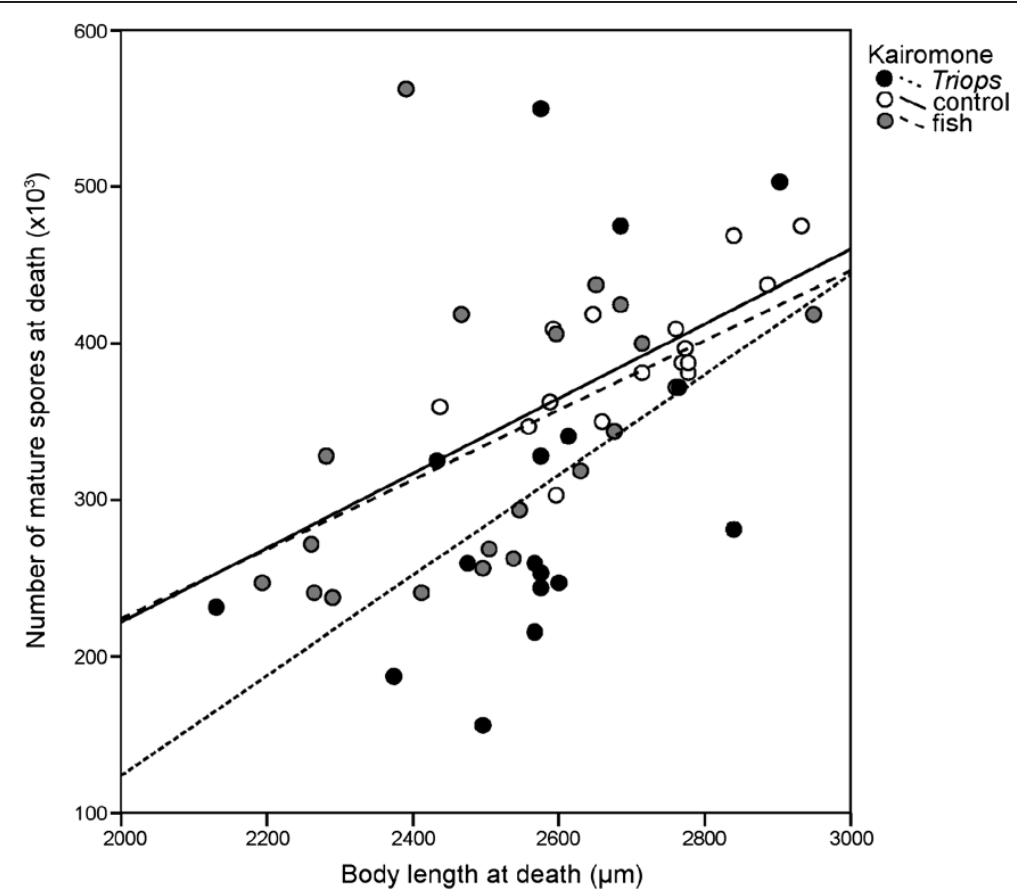

Figure 3 Number of parasite spores counted for each infected Daphnia magna in relation to its body length at death. Trend lines are drawn for each type of medium (Triops kairomone, control, fish kairomone).

It has been reported that exposure to fish kairomones can cause higher susceptibility to infection in another Daphnia species [24], and that D. magna have an increased risk of infection when they sink to lower depth to escape fish predation [50]. Conversely, other studies found that Daphnia resistance and/or parasite virulence remain unaffected by simultaneous exposure of the Daphnia host to fish kairmones [23,25]. In our study parasite spore load did not differ between predatorexposed and predator-naive Daphnia. Instead, we show that simultaneous exposure of Daphnia to parasites and predator kairomones can result in synergistic effects; this was most pronounced by the reduction in body length: double-stressed individuals were smallest (in all three clutches) and produced the smallest offspring (in the third clutch). The most interesting pattern in our experiment was the offspring body length, where the Triopsinduced response (but not the fish-response) was suppressed by infection. A reduced body length may impose particularly high costs for Triops-exposed Daphnia as they need to grow large to be successfully protected against this invertebrate predator [31,33]. Moreover, there might be some other costly defences against Triops that have not been assessed in our study. It has been shown that Daphnia strengthen their carapace by developing a thicker armour as protection against this invertebrate predator [51], a response also observed for Triops-exposed D. magna (Rabus et al., in preparation). These aspects might explain why only the defences against Triops, but not against fish, were suppressed by additional parasite stress. The Triops-induced response seems to require more resources which might have already been invested into parasite defence. Indeed, raising the immune defence is considered costly for invertebrates [52]. In contrast, a reduction in body length results in an even stronger defence against fish predation [23-25] and for fish-induced Daphnia, remaining small and producing smaller offspring does not require additional resources. However, smaller Daphnia have a lower feeding rate and thus take up fewer resources than bigger individuals [53]. Moreover, smaller Daphnia are also morphologically limited by the size of their brood pouch and therefore produce smaller eggs [54]. Hence, the latter aspects may therefore account for a lower fitness also in the case of fish- and parasite-exposed Daphnia.

There might be costs involved in other traits that were not tested in this study. For instance, diel vertical migration, a behavioral defence response of Daphnia under fish predation [e.g. $[55,56]]$, has been shown to be altered by parasite infection [57]. Moreover, since immune systems are highly plastic we cannot rule out that the investment into fighting off the parasite differed between the two predators the Daphnia were exposed to. In damselflies, for instance, it has been shown that risk of water mite parasitism and predation by dragonflies can increase investment into immunity [19]. However, since our study did not aim to measure the immune 
response it remains speculative if fighting off the parasite under different predator regimes results in a variable amount of resources available for the expression of defensive traits.

\section{Conclusions}

In nature, the result of combined predator and parasite stress seems to be variable as has been shown solely for multipredator scenarios e.g. [58,59]. Here the development of each trait is assumed to depend on its benefits and costs in the current environment since investment into a specific defence in the context of varying stressors is always a trade-off [60]. The presence and extent of the costs of inducible defences are still being debated. Theoretical models assume that inducible defences should be costly, as organisms would otherwise be constitutively defended [e.g. [6,7]]. However, many empirical studies find only negligible or weak costs (reviewed in [8]). We think that adding parasite pressure to studies of predator-prey systems can be a useful tool to elucidate the nature and extent of these costs. Our results suggest that Daphnia which express inducible defences against smaller invertebrate predators suffer more from an additional stressor, here parasites, than Daphnia expressing inducible defences against large vertebrate predators, at least for the traits measured in this study. Further research on the interactions between parasites and inducible defences, including other levels of defence and also traits of the immune system is required in order to reveal general patterns. The simultaneous impact of different threats may have important effects on species interactions in natural ecosystems.

\section{Competing interests}

There are neither financial nor non-financial competing interests involved in this study.

\section{Authors' contributions}

All authors were involved in designing the study. $\mathrm{OH}$ and WE performed the experiment and analysed the data. $\mathrm{OH}$ wrote the manuscript with the support of CL and JW. All authors read and approved the final manuscript.

\section{Authors information}

Christian Laforsch and Justyna Wolinska share senior authorship.

\section{Acknowledgements}

We thank M. Kredler and E. Ossipova for help during the experiments. Jennifer Lohr, two anonymous reviewers and the members of the Laforsch group provided comments on the manuscript. This research was funded by a DFG grant to CL and JW (LA 2159/5-1). OH was funded by a research scholarship provided by the Universität Bayern e.V.

Received: 27 March 2012 Accepted: 11 June 2012

Published: 24 July 2012

\section{References}

1. Tollrian R, Harvell CD: The ecology and evolution of inducible defenses. Princeton: Princeton University Press; 1999.

2. Lively CM: Canalization versus developmental conversion in a spatially variable environment. Am Nat 1986, 128(4):561-572.
3. Dicke M, Sabelis MW: Infochemical terminology: based on cost-benefit analysis rather than origin of compounds? FunctEcol 1988, 2(2):131-139.

4. Laforsch C, Beccara L, Tollrian R: Inducible defenses: The relevance of chemical alarm cues in Daphnia. Limnol Oceanogr 2006, 51(3):1466-1472.

5. Schoeppner NM, Relyea RA: Interpreting the smells of predation: how alarm cues and kairomones induce different prey defences. Funct Ecol 2009, 23(6):1114-1121.

6. Frank SA: A model of inducible defense. Evolution 1993, 47(1):325-327.

7. Riessen HP: Cost-benefit model for the induction of an antipredator defense. Am Nat 1992, 140:349-362.

8. Auld JR, Agrawal AA, Relyea RA: Re-evaluating the costs and limits of adaptive phenotypic plasticity. Proc R Soc B-Bio/Sci 2010, 277(1681):503-511.

9. De Witt TJ: Costs and limits of phenotypic plasticity: tests with predatorinduced morphology and life history in a freshwater snail. $J$ Evol Biol 1998, 11(4):465-480.

10. Gilbert JJ: Further observations on developmental polymorphism and its evolution in the rotifer Branchionus calyciflorus. Freshw Biol 1980, 10(3):281-294

11. Barry MJ: The effects of a pesticide on inducible phenotypic plasticity in Daphnia. Environ Pollut 1999, 104(2):217-224.

12. Lafferty KD, Dobson AP, Kuris AM: Parasites dominate food web links. Proc Natl Acad Sci USA 2006, 103(30):11211-11216.

13. Coslovsky $M$, Richner $\mathrm{H}$ : Increased predation risk on mothers affects survival of parasites feeding on the offspring. Anim Behav 2011, 81(5):1071-1075.

14. Han BA, Searle CL, Blaustein AR: Effects of an infectious fungus, Batrachochytrium dendrobatidis, on amphibian predator-prey interactions. PLoS One 2011, 6(2):e16675.

15. Luong LT, Hudson PJ, Braithwaite VA: Parasite-induced changes in the anti-predator behavior of a cricket intermediate host. Ethology 2011, 117(11):1019-1026.

16. Rigby MC, Jokela J: Predator avoidance and immune defence: costs and trade-offs in snails. Proc R Soc London, Ser B 2000, 267(1439):171-176.

17. Zhang J-X, Cao C, Gao H, Yang Z-S, Sun L, Zhang Z-B, Wang Z-W: Effects of weasel odor on behavior and physiology of two hamster species. Physiol Behav 2003, 79(4-5):549-552.

18. Stoks R, De Block M, Slos S, VanDoorslaer W, Rolff J: Time constraints mediate predator-induced plasticity in immune function, condition, and life history. Ecology 2006, 87(4):809-815.

19. Joop G, Rolff J: Plasticity of immune function and condition under the risk of predation and parasitism. Evol Ecol Res 2004, 6(7):1051-1062

20. Laforsch C, Tollrian R: In Cyclomorphosis and phenotypic changes, Encyclopedia of Inland Waters, Volume 3. Edited by Likens GE. Oxford: Elsevier; 2009:643-650

21. Ebert D: Ecology, epidemiology, and evolution of parasitism in Daphnia [Internet]. Bethesda (MD): National Library of Medicine (US): National Center for Biotechnology Information; 2005.

22. Ebert D: Host-parasite coevolution: insights from the Daphnia-parasite model system. Curr Opin Microbiol 2008, 11:1-12.

23. Lass $S$, Bittner K: Facing multiple enemies: parasitised hosts respond to predator kairomones. Oecologia 2002, 132(3):344-349.

24. Yin M, Laforsch C, Lohr J, Wolinska J: Predator-induced defence makes Daphnia more vulnerable to parasites. Evolution 2011, 65(5):1482-1488.

25. Coors A, De Meester L: Fitness and virulence of a bacterial endoparasite in an environmentally stressed crustacean host. Parasitology 2011, 138(01):122-131.

26. Coors A, De Meester L: Synergistic, antagonistic and additive effects of multiple stressors: predation threat, parasitism and pesticide exposure in Daphnia magna. J Appl Ecol 2008, 45(6):1820-1828.

27. Beckerman AP, Rodgers GM, Dennis SR: The reaction norm of size and age at maturity under multiple predator risk. J Anim Ecol 2010, 79(5):1069-1076.

28. Gosline A, Rodd F: Predator-induced plasticity in guppy (Poecilia reticulata) life history traits. Aquat Ecol 2008, 42(4):693-699.

29. Boersma M, Spaak P, De Meester L: Predator-mediated plasticity in morphology, life history, and behavior of Daphnia: the uncoupling of responses. Am Nat 1998, 152(2):237-248.

30. Sakwinska O: Plasticity of Daphnia magna life history traits in response to temperature and information about a predator. Freshw Biol 1998, 39(4):681-687 
31. Rabus M, Laforsch C: Growing large and bulky in the presence of the enemy: Daphnia magna gradually switches the mode of inducible morphological defences. Funct Ecol 2011, 25(5):1137-1143.

32. Waterkeyn A, Vanschoenwinkel B, Grillas P, Brendonck L: Effect of salinity on seasonal community patterns of Mediterranean temporary wetland crustaceans: a mesocosm study. Limnol Oceanogr 2010, 55(4):1712-1722

33. Rabus M, Waterkeyn A, Van Pottelbergh N, Brendonck L, Laforsch C Interclonal variation, effectiveness and long-term implications of Triops-induced morphological defences in Daphnia magna Strauss. J Plankton Res 2012, 34(2):152-160.

34. Wolinska J, Giessler S, Koerner H: Molecular identification and hidden diversity of novel Daphnia parasites from European lakes. Appl Environ Microbiol 2009, 75(22):7051-7059.

35. Ebert $D$, Lipsitch $M$, Mangin KL: The effect of parasites on host population density and extinction: Experimental epidemiology with Daphnia and six microparasites. Am Nat 2000, 156(5):459-477.

36. Hall SR, Simonis JL, Nisbet RM, Tessier AJ, Caceres CE: Resource ecology of virulence in a planktonic host-parasite system: an explanation using dynamic energy budgets. Am Nat 2009, 174(2):149-162.

37. Lohr J, Yin M, Wolinska J: Prior residency does not always pay off - coinfections in Daphnia. Parasitology 2010, 137:1493-1500.

38. Boix D, Sala J, Moreno-Amich R: Population dynamics of Triopscancriformis (Crustacea: Branchiopoda: Notostraca) of the Espolla temporary pond in the northeastern Iberian peninsula. Hydrobiologia 2002, 486(1):175-183.

39. Green J: Parasites and epibionts of cladoceran. Trans Zool Soc Lond 1974, 32:417-515

40. Harter HL: Expected values of normal order statistics. Biometrika 1961, 48(1-2):151-165.

41. Harvell CD: Genetic variation and polymorphism in the inducible spines of a marine bryozoan. Evolution 1998, 52(1):80-86.

42. Wiackowski K, Fyda J, Pajdak-Stos A, Adamus K: Predator-induced morphological defence in ciliates: Interclonal variation for sensitivity to the inducing factors. Oikos 2003, 100(3):534-540.

43. Agrawal AA, Laforsch C, Tollrian R: Transgenerational induction of defences in animals and plants. Nature 1999, 401(6748):60-63.

44. Laforsch C, Tollrian R: Embryological aspects of inducible morphological defenses in Daphnia. J Morphol 2004, 262(3):701-707.

45. Alekseev $V$, Lampert W: Maternal effects of photoperiod and food level on life history characteristics of the cladoceran Daphnia pulicaria Forbes. Hydrobiologia 2004, 526(1):225-230.

46. Gliwicz ZM, Guisande C: Family planning in Daphnia: resistance to starvation on offspring born to mothers grown at different food levels. Oecologia 1992, 91(4):463-467.

47. Allen RM, Buckley YM, Marshall DJ: Offspring size plasticity in response to intraspecific competition: an adaptive maternal effect across life-history stages. Am Nat 2008, 171(2):225-237.

48. Hendrickx F, Maelfait JP, Speelmans M, Van Straalen NM: Adaptive reproductive variation along a pollution gradient in a wolf spider. Oecologia 2003, 134(2):189-194.

49. Shostak AW: Tapeworm (Hymenolepis diminuta) infection in flour beetles (Tribolium confusum): does it cause a trade-off between host fecundity and egg size? Can. J Zool 2009, 87(11):1087-1095.

50. Decaestecker E, De Meester L, Ebert D: In deep trouble: habitat selection constrained by multiple enemies in zooplankton. Proc Natl Acad Sci USA 2002, 99:5481-5485.

51. Laforsch C, Ngwa W, Grill W, Tollrian R: An acoustic microscopy technique reveals hidden morphological defenses in Daphnia. Proc Natl Acad Sci USA 2004, 101(45):15911-15914.

52. Carton Y, Nappi AJ, Poirie M: Genetics of anti-parasite resistance in invertebrates. Dev Comp Immunol 2005, 29(1):9-32.

53. Kooijman SALM: Dynamic energy budgets in biological systems: Theory and applications in ecotoxicology. The Pitt Building, Trumpington Street, Cambridge CB2 1RP, England; 40 W. 20th Street, New York, New York 10011-4211, USA: Cambridge University Press; 1993.

54. Glazier DS: Effects of food, genotype, and maternal size and age on offspring investment in Daphnia magna. Ecology 1992, 73(3):910-926.

55. De Meester L, Cousyn C: The change in phototacticbehaviour of a Daphnia magna clone in the presence of fish kairomones: the effect of exposure time. Hydrobiologia 1997, 360:169-175.
56. De Meester L, Weider LJ, Tollrian R: Alternative antipredatordefences and genetic polymorphism in a pelagic predator-prey system. Nature 1995, 378(6556):483-485.

57. Fels D, Lee VA, Ebert D: The impact of microparasites on the vertical distribution of Daphnia magna. Arch Hydrobiol 2004, 161(1):65-80.

58. Hoverman JT, Relyea RA: The rules of engagement: How prey defend themselves against combinations of predators. Oecologia 2007, 154:551-560.

59. Hoverman JT, Relyea RA: Survival trade-offs associated with inducible defences in snails: the roles of multiple predators and developmental plasticity. Funct Ecol 2009, 23(6):1179-1188.

60. Steiner Ulrich $\mathrm{K}$, Pfeiffer T: Optimizing time and resource allocation trade-offs for investment into morphological and behavioral defense. Am Nat 2007, 169(1):118-129.

doi:10.1186/1472-6785-12-12

Cite this article as: Hesse et al:: Fighting parasites and predators: How to deal with multiple threats?. BMC Ecology 2012 12:12.

\section{Submit your next manuscript to BioMed Central and take full advantage of:}

- Convenient online submission

- Thorough peer review

- No space constraints or color figure charges

- Immediate publication on acceptance

- Inclusion in PubMed, CAS, Scopus and Google Scholar

- Research which is freely available for redistribution 